SALGADO, R.L. et al. Uso de embalagem em atmosfera modificada na conservação do pescado: Revisão bibliográfica. PUBVET, Londrina, V. 5, N. 1, Ed. 148, Art. 994, 2011.

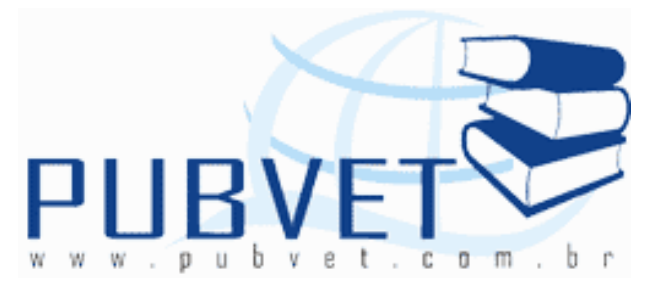

PUBVET, Publicações em Medicina Veterinária e Zootecnia.

\title{
Uso de embalagem em atmosfera modificada na conservação do pescado - Revisão bibliográfica
}

\section{Raquel Lima Salgado1,3; Juliana de Castro Beltrão da Costa²; Fernanda Lima Cunha $^{3}$; Rogério Tortelly ${ }^{4}$; Sérgio Borges Mano ${ }^{4}$}

${ }^{1}$ Docente do curso de graduação em Zootecnia da Universidade Federal Rural da Amazônia - UFRA / PA

${ }^{2}$ Médica Veterinária

3 Doutorandas do Programa de Pós-graduação em Higiene Veterinária e Processamento Tecnológico de P.O.A. - UFF

${ }^{4}$ Docentes da Universidade Federal Fluminense - UFF / RJ

\section{Resumo}

Os peixes são alimentos altamente perecíveis, e em condições normais de refrigeração, a conservação destes produtos está limitada pelos processos de deterioração enzimática e microbiológica. Em função do reduzido prazo de vida comercial, a crescente demanda por produtos frescos, e ainda, com a necessidade de redução de custos relacionados à energia utilizada nos processos de refrigeração e congelamento, justifica-se a busca por tecnologias que permitam um aumento no prazo de vida comercial de alimentos altamente perecíveis e com alto teor protéico, como peixes. Uma alternativa para solucionar este problema é o uso de embalagens em atmosfera modificada. $\mathrm{O}$ objetivo desta revisão é elucidar de que forma o uso de embalagens contendo 
SALGADO, R.L. et al. Uso de embalagem em atmosfera modificada na conservação do pescado: Revisão bibliográfica. PUBVET, Londrina, V. 5, N. 1, Ed. 148, Art. 994, 2011.

atmosferas modificadas pode influenciar o prazo de conservação do pescado, por retardar as diversas modificações que caracterizam a sua perda de qualidade.

Palavras-chave: atmosfera modificada; pescado; vida comercial.

\title{
Use of modified atmosphere package in seafood preservation
}

\begin{abstract}
Fish are highly perishable foods, and in normal conditions of refrigeration, the shelf life of these products is limited by the enzymatic and microbiological processes of deterioration. In function of the reduced shelf-life, the increasing demand for fresh products, and still, with the necessity of reduction of costs related to the energy used in the processes of refrigeration and freezing, is justified searchs for technologies that allow an increase in the shelf-life of highly perishable foods and with high proteic text, as fish. An alternative to solve this problem is the use of modified atmosphere packaging. The objective of this review is to elucidate how the modified atmosphere packaging can influence the shelf-life of the seafood, for delaying the modifications that characterize the loss of its quality.
\end{abstract}

Keywords: modified atmosphere; fished; shelf-life

\section{INTRODUÇÃO}

A carne de pescado é uma fonte de proteínas de alto valor biológico, com teor satisfatório de gorduras insaturadas, vitaminas e minerais, além de ser um alimento de alta digestibilidade. Dentre seus principais componentes químicos estão a água, proteína bruta e lipídeos, que juntos somam cerca de $98 \%$ do peso total da carne (SIKORSKI, 1990). Estes componentes são de máxima importância por influenciarem diretamente o valor nutricional, a qualidade sensorial e a vida útil dos produtos da pesca, sendo a degradação 
SALGADO, R.L. et al. Uso de embalagem em atmosfera modificada na conservação do pescado: Revisão bibliográfica. PUBVET, Londrina, V. 5, N. 1, Ed. 148, Art. 994, 2011.

proteica e a oxidação lipídica os principais responsáveis por alterações nestes atributos.

A deterioração ou as alterações autolíticas são as principais responsáveis pela perda da qualidade inicial do pescado fresco, principalmente devido ao rápido desenvolvimento de odores desagradáveis e ao aparecimento de manchas devido à ação de enzimas digestivas. A alteração autolítica mais importante é a redução do óxido de trimetilamina (OTMA) em trimetil amina (TMA), que ocorre por ação de bactérias em peixes refrigerados, enquanto no pescado congelado a atividade bacteriana é inibida e o OTMA é convertido em dimetilamina e formoldeído por enzimas autolíticas (HUSS, 1995).

Conforme o processo de degradação avança, o pH muscular aumenta superando o valor da neutralidade, permitindo a liberação de quantidades cada vez maiores de amoníaco, contribuindo para criar o odor típico de pescado decomposto. Sem duvida, a causa predominante do odor amoniacal é a TMA, originaria da degradação do OTMA, no entanto outros produtos do metabolismo bacteriano também contribuem na percepção sensorial da degradação, como os ácidos graxos de cadeia curta (ácido lático e o ácido butírico); os aldeídos e cetonas dos lipídios tissulares; aminas como o indol, o escatol, a histamina, a putrescina e a cadaverina; assim como o amoníaco procedente dos aminoácidos e proteínas (RUITER, 1995).

Sensorialmente estas alterações podem ser observadas quando o pescado fresco deixa de apresentar um sabor à algas marinhas, doce e delicado, um odor característico, carne firme, elástica, de coloração translúcida, uniforme e brilhante. Com o início do processo de deterioração formam-se compostos com odor e sabor ácidos, tendendo a ervas ou frutas, e mais tarde aparecem substâncias amargas, de aspecto gomoso e aroma sulfuroso, culminando com o caráter amoniacal e fecal, característico do estado pútrido; sendo os microrganismos os principais agentes responsáveis pela origem de sabores e odores indesejáveis (HUSS, 1995).

A microbiota do pescado vivo está diretamente relacionada às águas onde ele habita. Na pesca marítima, a captura de peixes em águas costeiras 
SALGADO, R.L. et al. Uso de embalagem em atmosfera modificada na conservação do pescado: Revisão bibliográfica. PUBVET, Londrina, V. 5, N. 1, Ed. 148, Art. 994, 2011.

oferece maiores riscos do que a realizada em alto mar, em conseqüência da poluição dos grandes centros e das desembocaduras de redes de esgoto próximas à costa, promovendo a adição de microrganismos oriundos de matéria fecal à superfície do pescado (EIROA, 1980; LIMA, 1997).

No muco que recobre a superfície externa do pescado já foram isoladas bactérias dos gêneros Pseudomonas, Acinetobacter, Moraxella, Alcaligenes, Micrococcus, Flavobacterium, Corynebacterium, Sarcina, Serratia, Vibrio, Bacillus e pertencentes à família Enterobacteriaceae. Os microrganismos encontram-se tanto nas superfícies externas (pele e brânquias), como nos intestinos dos peixes vivos e recém capturados (HUSS, 1995).

São muitos os microrganismos que habitam o trato digestivo dos animais marinhos e, inevitavelmente, muitos se dispersam pela cavidade abdominal durante a evisceração. A baixa tensão de oxigênio nos intestinos explica a existência de uma diferente distribuição de grupos bacterianos, onde as cepas de Vibrio estão em maior quantidade e acredita-se haver uma pequena quantidade de anaeróbios restritos, como o Clostridium spp. (RUITER, 1995).

Dentre os microrganismos mais importantes destacam-se os do gênero Vibrio, onde o Vibrio parahaemolyticus está usualmente presente nas águas costeiras do mar (LIMA, 1997); bactérias do gênero Salmonella spp, comumente encontradas em águas poluídas por esgotos ou excretas de animais (GERMANO et al., 1993); Streptococcus sp. e Staphylococcus aureus podem estar presentes nas mucosas e superfície da pele, onde encontram ambiente favorável para sua multiplicação, e são conseqüência direta da manipulação inadequada (GERMANO et al., 1998).

O peixe absolutamente fresco e íntegro é impermeável a bactérias devido à pele intacta. Após a morte, a autólise se instala, tornando a pele do peixe permeável às bactérias e ao mesmo tempo liberando açúcares simples, aminoácidos livres, entre outras substâncias, provendo um meio rico em nutrientes para o crescimento bacteriano (MUKUNDAN et al., 1986). Durante os primeiros dias de armazenamento em gelo, a população bacteriana se concentra na superfície do pescado. A lenta penetração no tecido muscular 
SALGADO, R.L. et al. Uso de embalagem em atmosfera modificada na conservação do pescado: Revisão bibliográfica. PUBVET, Londrina, V. 5, N. 1, Ed. 148, Art. 994, 2011.

ocorre principalmente em pontos onde estejam presentes cortes e erosões, que facilitem o ingresso bacteriano. A taxa de penetração dependerá das características próprias da espécie pesqueira, podendo diferir muito entre uma espécie e outra (SIKORSKI, 1990).

Apesar de ser um alimento nutricionalmente rico, o pescado pode ser vinculador de uma grande variedade de microrganismos patogênicos ao homem, além de possuir um curto prazo de vida comercial, o que dificulta a sua comercialização a longas distâncias. De maneira geral, quando mantido sob refrigeração e gelo, a vida útil do pescado pode variar entre dois a 14 dias, dependendo da espécie, local de captura e estação do ano (STAMMEN et al., 1990).

Em função deste reduzido prazo de vida comercial, a crescente demanda por produtos frescos, e ainda, com a necessidade de redução de custos relacionados à energia utilizada nos processos de refrigeração e congelamento, justifica-se a busca por tecnologias que permitam um aumento no prazo de vida comercial de alimentos altamente perecíveis e com alto teor protéico, como peixes. Uma alternativa para solucionar este problema é o uso de embalagens em atmosfera modificada. O objetivo desta revisão é elucidar de que forma o uso de embalagens contendo atmosferas modificadas pode influenciar o prazo de conservação do pescado, por retardar as diversas modificações que caracterizam a sua perda de qualidade.

\section{REVISÃO DE LITERATURA}

\section{Embalagem em Atmosfera Modificada}

Tecnologias que lidam com a extensão, segurança, e tempo de vida comercial de alimentos altamente perecíveis e com alto teor protéico como o pescado, carnes vermelhas e produtos de aves, são de enorme significância econômica por possibilitarem transportes a longas distâncias mais econômicos, 
SALGADO, R.L. et al. Uso de embalagem em atmosfera modificada na conservação do pescado: Revisão bibliográfica. PUBVET, Londrina, V. 5, N. 1, Ed. 148, Art. 994, 2011.

redução de perdas em função da deterioração e conveniência para a indústria e consumidor (GENIGEORGIS, 1985).

A cada dia surgem novas tecnologias que permitem um aumento no prazo de vida comercial dos produtos e incremento nas suas características sensoriais, de modo a torná-los mais atrativos e de fácil acesso ao consumidor, especialmente no que tange a manutenção do seu estado de frescor (HINTLIAN e HOTCHKISS, 1986), em detrimento da demanda de consumo de alimentos enlatados e congelados (FARBER, 1991). Atendendo a esta demanda, tem-se investido em estudos de embalagens em atmosfera modificada (EAM).

Os métodos de conservação sob atmosfera modificada consistem nas diferentes maneiras pelas quais o dióxido de carbono é utilizado como conservante de alimentos. De um modo geral, a EAM é um processo hipobárico que consiste em alterar a atmosfera da câmara ou da embalagem, preenchendo-a com diferentes misturas de gás carbônico $\left(\mathrm{CO}_{2}\right)$ nitrogênio $\left(\mathrm{N}_{2}\right)$ e oxigênio $\left(\mathrm{O}_{2}\right)(\mathrm{JAY}, 2004)$.

\section{Breve histórico}

$\mathrm{O} \mathrm{CO}_{2}$ é conhecido desde a antiguidade. Em 1877 Pasteur e Jouber observaram que Bacillus anthracis poderia ser inibido por $\mathrm{CO}_{2}$ (VALLEY, 1928), e cinco anos mais tarde $K_{\text {Kolbe }}$ (1882, apud JAY,2004) publicou o primeiro artigo sobre o efeito do $\mathrm{CO}_{2}$ na preservação da carne bovina, mostrando que grandes quantidades de $\mathrm{CO}_{2}$ aumentam a vida de prateleira de carnes por quatro a cinco semanas. Em 1889 foi reconhecida a atividade antibacteriana do $\mathrm{CO}_{2}$, e em 1910 estabeleceu-se a utilização de embalagem em atmosfera modificada para conservar diversos alimentos (JAY, 2004).

Nos anos 30 surgiram novos estudos sobre atmosfera modificada impulsionados pela utilização do $\mathrm{CO}_{2}$ na conservação de carnes transportadas de navio a partir da Austrália e Nova Zelândia até a Inglaterra, como os

\footnotetext{
${ }^{I}$ KOLBE, H. Antiseptische eigenschaften der kohlensaure. Journal Für Praktische Chemie. V. 26, p. 249-255, 1882.
} 
SALGADO, R.L. et al. Uso de embalagem em atmosfera modificada na conservação do pescado: Revisão bibliográfica. PUBVET, Londrina, V. 5, N. 1, Ed. 148, Art. 994, 2011.

realizados por Killefer (1930), Coyne (1932) e Stansby e Griffiths (1935). Em 1938 aproximadamente $26 \%$ da carne de gado comercializada na Nova Zelândia e $60 \%$ da carne comercializada na Austrália eram transportadas por navios sob atmosferas de $\mathrm{CO}_{2}$ (SORHEIM e NISSEN, 2005). Esse aumento estava relacionado às então novas tecnologias de embalagens, com desenvolvimento de polímeros e equipamentos de termo-moldagem de empacotamento (WOLFE, 1980).

Nos anos 70, com o avanço de embalagens individuais para um público cada vez mais exigente, a tecnologia de embalagem em atmosfera modificada (EAM) apresentou um grande impulso (WOLFE, 1980). Em 1974 foi introduzida a EAM no comércio varejista de alimentos de origem animal na França (CHURCH, 1994).

Em 1980 Brown et al. revisaram o efeito da temperatura, solubilidade e inibição de $\mathrm{CO}_{2}$ e concluíram que, ao contrário do mecanismo sinérgico entre temperatura e solubilidade, todas as evidências apontam que o aumento de temperatura reduz a solubilidade e aumenta o crescimento microbiano.

Desde a década de 80,90 , até os dias de hoje, muita produção bibliográfica foi desenvolvida a respeito do tema embalagem sob atmosfera modificada. Revisões feitas por Wolfe (1980); Pedrosa-Menabrito e Regenstein (1988); Stammen et al. (1990); Church e Parsons (1995); e Siversvik et al. (2002) documentaram a habilidade da EAM de aumentar a duração do tempo de prateleira de vários produtos perecíveis, como carne, aves e pescado.

A tecnologia de EAM é atualmente difundida em praticamente todos os países desenvolvidos, e cerca de $10 \%$ a $40 \%$ dos produtos de origem animal já são comercializados sob EAM. A Noruega é o país onde se verifica a maior proporção de alimentos comercializados sob EAM, com aproximadamente $60 \%$ do total do país (SORHEIM e NISSEN,2005). 
SALGADO, R.L. et al. Uso de embalagem em atmosfera modificada na conservação do pescado: Revisão bibliográfica. PUBVET, Londrina, V. 5, N. 1, Ed. 148, Art. 994, 2011.

\section{Principais gases utilizados}

O método de embalagem em atmosfera modificada consiste em substituir a atmosfera que rodeia o produto por um gás ou mistura de gases, especialmente desenvolvidos para cada tipo de alimento.

De acordo com Genigeorgis (1985) existem basicamente três categorias de atmosfera modificada usadas na preservação de alimentos: a modificação da atmosfera através da técnica de embalagem, como a embalagem a vácuo; a redução da pressão atmosférica dentro do container para que se possa alcançar uma condição de estocagem hipobárica; e a modificação da atmosfera através do enriquecimento da embalagem ou container pela adição de uma variedade de gases ou mistura desses. Nestas são utilizados diversos tipos de gases, cujos mais freqüentes são o dióxido de carbono $\left(\mathrm{CO}_{2}\right)$, o nitrogênio $\left(\mathrm{N}_{2}\right)$ e o oxigênio $\left(\mathrm{O}_{2}\right)$.

O dióxido de carbono exerce um forte efeito inibidor sobre o crescimento bacteriano, sendo particularmente efetivo contra as bactérias aeróbias Gram negativas da decomposição, tais como Pseudomonas e Shewanella, que provocam alterações de cor e odor em carnes, aves e pescados $(\mathrm{CHURCH}$, 1994). Estudos comprovam que mesmo quando utilizado em baixas concentrações (20\%) $0 \quad \mathrm{CO}_{2}$ produz efeitos eficientes na preservação do pescado (BROWN et al., 1980). Parry (1993) afirma que as concentrações de $\mathrm{CO}_{2}$ acima de $5 \%$ inibem o crescimento da maior parte das bactérias causadoras de deterioração, especialmente as psicrófilas, que crescem em grande parte de alimentos refrigerados.

Em peixes, o estudo de misturas gasosas mais convenientes para a conservação e otimização do armazenamento ainda não está totalmente definido, assim como as modificações na caracterização sensorial e nos parâmetros físico-químicos de várias espécies quando embaladas em atmosfera modificada, entretanto a mais promissora parece ser a atmosfera enriquecida com altas concentrações de $\mathrm{CO}_{2}$. 
SALGADO, R.L. et al. Uso de embalagem em atmosfera modificada na conservação do pescado: Revisão bibliográfica. PUBVET, Londrina, V. 5, N. 1, Ed. 148, Art. 994, 2011.

Stammen et al. (1990) afirmam ainda que elevadas concentrações de dióxido de carbono em embalagem em atmosfera modificada têm demonstrado boa inibição da microbiota normal de decomposição do pescado, duplicando ou triplicando o seu prazo de vida comercial.

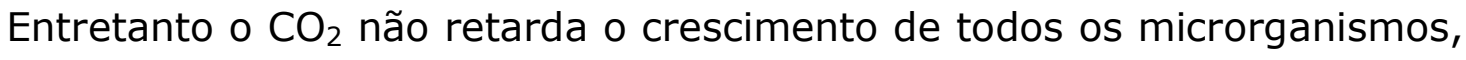
e seu efeito inibidor aumenta com a diminuição da temperatura, em decorrência do aumento da sua solubilidade (STAMMEN et al., 1990; PARRY, 1993; SIVERSTIVIK et al., 2002).

O nitrogênio é um gás insípido, incolor, inodoro e insolúvel em gordura e água, sendo utilizado, principalmente, para substituir o oxigênio, retardando a oxidação e prevenindo o aparecimento do ranço. Indiretamente também pode influenciar na preservação de produtos perecíveis, por dificultar o desenvolvimento dos microrganismos aeróbios responsáveis pela decomposição. Também é usado para manter a integridade da embalagem comercial, evitando o colapso ocasionado pela diferença de pressão pela retirada do ar, em alimentos que consomem $\mathrm{CO}_{2}(\mathrm{CHURCH}, 1994)$.

O oxigênio é o responsável pela coloração vermelha-brilhante da carne fresca, por se ligar à hemoglobina formando o complexo oximioglobina, sendo utilizado em embalagens com o intuito de melhorar a aparência dos produtos cárneos (PHILLIPS, 1996). Sua ausência gera uma coloração amarronzada, em decorrência da formação do pigmento metamioglobina. No entanto, a presença do $\mathrm{O}_{2}$ em grandes proporções induz ao aparecimento do ranço, devendo ser evitado, principalmente em peixes gordos, por favorecer o processo de rancificação oxidativa (STAMMEN et al., 1990), gerando sabor e odor desagradáveis, levando a uma redução no prazo de vida comercial desses produtos.

A eficiência do $\mathrm{CO}_{2}$ na conservação do pescado foi constatado por Killefer (1930) que observou um aumento de 2 a 3 vezes na vida útil do pescado fresco. Resultado semelhante ao encontrado por Özogul et al. (2004) ao estudarem o efeito da embalagem em atmosfera modificada (EAM) nas alterações químicas, sensoriais e microbiológicas de sardinhas (Sardina 
SALGADO, R.L. et al. Uso de embalagem em atmosfera modificada na conservação do pescado: Revisão bibliográfica. PUBVET, Londrina, V. 5, N. 1, Ed. 148, Art. 994, 2011.

pilchardus) mantidas sob refrigeração, e determinaram que a EAM aumentou o prazo de vida comercial de três dias quando estocadas em ar atmosférico, para 12 dias quando estocadas em EAM.

Ordoñez et al. (2000) estudaram as mudanças microbiológicas e físicoquímicas de files de merluza (Merluccius merluccious) estocadas em atmosferas enriquecidas com dióxido de carbono, concluindo que a atmosfera de $40 \%$ de $\mathrm{CO}_{2}$ e $60 \%$ de ar é a recomendada para a embalagem de merluza sobre refrigeração, o que pode resultar em um aumento na vida comercial de até três vezes, tanto sob o ponto de vista microbiológico, quanto sensorial.

Avaliando amostras de carne de rã, Conte-Júnior et al. (2003) concluíram que o uso de atmosfera modificada contendo $80 \%$ de $\mathrm{CO}_{2}$ na preservação de carne de rã aumentou de forma satisfatória a vida útil do produto. Corroborando com o referido autor, Lopes et al. (2004), utilizando amostras de sardinhas (Sardinella brasiliensis), concluiu que, do ponto de vista microbiológico, as embalagens enriquecidas $\mathrm{com} \mathrm{CO}_{2}$ demonstraram os melhores resultados. Atentou também para os resultados das bases voláteis totais que, se consideradas em conjunto com a inibição microbiana, foram decisivos para definir o prazo de vida útil do produto.

Poli et al. (2006) ao estudarem as alterações sensoriais, físicas, químicas e microbiológicas em Robalo (Dicentrarchus labrax) embalado em atmosfera modificada e em ar, encontraram altos indícios de desenvolvimento bacteriano nos primeiros dias de estocagem em aerobiose, alcançando valores acima de Log $6 \mathrm{UFC} / \mathrm{g}$ no $5^{\circ}$ dia de estocagem em ar e no $8^{\circ}$ em EAM.

Soccol et al. (2005) compararam o efeito da embalagem em atmosfera modificada e a vácuo na conservação filés de tilápia (Oreochromis niloticus), e concluíram que as atmosferas enriquecidas $\mathrm{com} \mathrm{CO}_{2}$ demonstraram melhor desempenho.

Muitos autores estudaram o comportamento de microrganismos heterotróficos aeróbios mesófilos em pescado, como Reddy et al. (1994) e Reddy et al. (1995), ao estudarem filés de tilápia (Oreochromis nilótica), López-Gálvez et al. (1995), trabalhando com filés de Atum (Thunnus alalunga), 
SALGADO, R.L. et al. Uso de embalagem em atmosfera modificada na conservação do pescado: Revisão bibliográfica. PUBVET, Londrina, V. 5, N. 1, Ed. 148, Art. 994, 2011.

e Sivertsvik et al. (2003) estudando filés de salmão (Salmo salar), e todos observaram um aumento de vida útil destes produtos quando submetidos à ação do $\mathrm{CO}_{2}$ em variadas concentrações.

A utilização do $\mathrm{CO}_{2}$ na conservação de alimentos é comprovadamente eficaz, no entanto estudos demonstram que altas concentrações de $\mathrm{CO}_{2}$ dissolvidos na fase aquosa do músculo de pescado embalado em atmosfera modificada, promovem uma acidificação tecidual, e conseqüente diminuição na capacidade de retenção de água das proteínas musculares, ocasionando um aumento nas perdas por gotejamento (HUSS, 1995; PASTORIZA, et al., 1998).

Conforme comprovado por Albanese et al. (2005) que ao estudarem as alterações químicas e microbiológicas apresentadas por Sépias (Sepia officinalis) em EAM verificaram o aparecimento do "drip" a partir do $5^{\circ}$ dia de estocagem, contabilizando uma perda final de $2,5 \%$ do peso total do pescado.

Já Church (1994) evidenciou uma redução na qualidade da textura do músculo do pescado armazenado em altas concentrações de $\mathrm{CO}_{2}$.

Apesar dessas implicações, a aplicação da tecnologia de atmosfera modificada vem crescendo a cada ano. Em 1994 cerca de 95\% de toda a massa fresca e $10 \%$ dos frutos do mar vendidos no Reino Unido era embalada em atmosfera modificada (Church, 1994), e em 2005 60\% dos alimentos comercializados na Noruega estavam sob EAM (SORHEIM e NISSEN,2005).

\section{Características do material de envase}

O sucesso da utilização da EAM está intimamente relacionado à qualidade dos materiais utilizados no envase do produto. Estes têm como finalidade manter a atmosfera interna isolada do ambiente externo, e devem possuir características específicas como: resistência à abrasão, ruptura e perfuração; espessura adequada a fim de evitar microporos; e transparência, permitindo sempre a visualização do produto.

Os polímeros mais utilizados em EAM são o polietileno, a poliamida, o polipropileno, o poliestireno, o cloreto de polivinil (PVC), o cloreto de 
SALGADO, R.L. et al. Uso de embalagem em atmosfera modificada na conservação do pescado: Revisão bibliográfica. PUBVET, Londrina, V. 5, N. 1, Ed. 148, Art. 994, 2011.

polivinileno, o poliéster, o etilvinilálcool, e as combinações entre estes, com o intuito de melhorar a eficiência do filme (STAMMEN, 1990). No presente estudo foi utilizado um filme de polietileno BBL4, multicamadas e de baixa permeabilidade, da empresa "Cryovac".

\section{CONCLUSÕES}

Devido ao crescente consumo mundial de pescado, faz-se necessário agregar qualidade a estes alimentos e garantir que sejam inócuos ao consumo humano. Neste contexto 0 uso de embalagens contendo atmosferas modificadas é uma solução viável economicamente para as indústrias pesqueiras, possuindo grande efetividade na conservação de pescado sob refrigeração, aumentando seu prazo de vida comercial em até três vezes, gerando benefícios para os produtores e consumidores.

\section{REFERÊNCIAS BIBLIOGRÁFICAS}

ALBANESE, D. et al. Squid (Sepia officinalis) stored in active packaging: some chemical and microbiological changes. Journal of Food Science, v.17, n.3, p.325-332, 2005.

BROWN, W. D. et al. Modified atmosphere storage of rockfish (Sebastus miniatus) and silver salmon (Onchorrynchus kisutch). Journal of Food Science, v.45, p.93-96, 1980.

$\mathrm{CHURCH}, \mathrm{N}$. Developments in modified-atmosphere packing and related technologies. Trends in Food Science and Technology, v.5, p.345-352, 1994.

CHURCH, I.; PARSONS, A. Modified atmosphere packaging technology: a Review. Journal of Science Food and Agriculture, v. 67, p. 143-152, 1995.

COYNE, F. P. The effect of carbon dioxide on bacterial growth with special reference to the preservation of fish. Part I. Journal of the Society of Chemical Industry, v. 52, p. 119$121,1932$.

EIROA, M. N. U. Aspectos microbiológicos relacionados à conservação e ao consumo de pescado. Boletim da Sociedade Brasileira Ciência e Tecnologia de Alimentos, Campinas, v.54 p. 9-37, 1980.

GENIGEORGIS, C. A. Microbial and safety implications of the use of modified atmposphere to extend the storage life of fresh meat and fish. International Journal of Food Microbiology, v.1, n.5, p.237-251, 1985.

GERMANO, P.M.L. et al. O pescado como causa de toxinfecções bacterianas. Revista Higiene Alimentar, v.7, n.28, p.40-45, 1993. 
SALGADO, R.L. et al. Uso de embalagem em atmosfera modificada na conservação do pescado: Revisão bibliográfica. PUBVET, Londrina, V. 5, N. 1, Ed. 148, Art. 994, 2011.

GERMANO, P.M.L. et al. Aspectos da qualidade do pescado de relevância em saúde pública. Revista Higiene Alimentar, v.7, n.53, 1998.

HUSS, H.H. Quality and quality changes in fresh fish. Roma: Food and Agriculture Organization of de united nations, 1995. 193p.(FAO fisheries technical paper, n.348).

JAY, J. M. Microbiologia de alimentos. Porto Alegre: Artmed, 2005. 711p.

KILLEFFER, D. H. Carbon dioxide preservation of meat and fish. Industrial \& Engineering Chemistry Research, v.22, n.2, p.140-143, 1930.

LIMA, F.C. Vibrios marinhos: 1. Vibrio parahaemolyticus. Revista Higiene Alimentar, v.11, n.47, p.14-22, 1997.

LÓPEZ-GÁLVEZ, D.; HOZ, L.;ORDÓNEZ, J. A. Effects of carbon dioxide and oxygen enriched atmospheres on microbiological and chemical in refrigerated tuna (Thunnus alalunga) steaks. Journal of Agriculture and Food Chemistry, v. 43, p. 483-490, 1995.

MUKUNDAN, M. K. et al A review on autolysis in fish. Fisheries Research, v.4, p. 259-269, 1986.

OgAWA, M.; MAIA, E.L. Manual de Pesca - Ciência e Tecnologia de Pescados. São Paulo: Livraria Varela, 1999. 430p.

ORDÖÑEZ, J. A. et al Microbial and physicochemical modifications of hake (Merluccius merluccius) stakes stored under carbon dioxide enriched atmosphere. Journal of the Science of Food and Agriculture, v. 80, p.1831-1840, 2000.

ÖZOGUL, F. et al. The effects of modified atmosphere packaging and vacuum packaging on chemical, sensory and microbiological changes of sardines (Sardina pilchardus ). Food Chemistry, v.85, p.49-57, 2004.

PARRY, R. T. Envasado de los alimentos en atmósfera modificada. Madrid: A Madrid Vicente, 1993. 541p.

PHILLIPS, C. A. Review: modified atmosphere packaging and its effects on the microbiological quality and safety of produce. International Journal of Food Science and Technologyn, $v$. 31, p. 1723-1728, 1996.

REDDY, N. R. et al. Shelf life of fresh tilápia fillets package in high barrier film with modified atmosphere. Journal of Food Science, v. 59, n. 2, p.260-264, 1994.

REDDY, N. R. et al. Shelf life of modified atmosphere package fresh tilápia fillets stored under refrigeration and temperature abuse conditions. Journal of Food Protection, v. 58, n. 8, p. 908-914, 1995.

RUITER, A. El pescado y los productos derivados de la pesca: composicíon, propriedades nutricionales y estabilidad. Zaragoza: Acribia, 1995. 647p.

SIKORSK, Z. E. Seafood: resources, nutritional composition, and preservation. Florida: CRC Press, 1990. 247p.

SIVERTSVIK, M.et al. A review of modified atmosphere packaging of fish and fisheries products - significance of microbial growth, activities and safety. International Journal of Food Science and Technologyn, v. 37, p. 1-7-127, 2002. 
SALGADO, R.L. et al. Uso de embalagem em atmosfera modificada na conservação do pescado: Revisão bibliográfica. PUBVET, Londrina, V. 5, N. 1, Ed. 148, Art. 994, 2011.

SIVERTSVIK, M. et al. The effect of modified atmosphere packaging and superchilled storage on the microbial and sensorial quality of atlantic salmon (Salmo sallar) fillets. Journal of Food Sciencen, v. 68, n. 4, p. 1467-1472, 2003.

SORHEIM, O.; NISSEN, H. Current technology for modified atmosphere packaging of meat. Capturado em 08 de janeiro de 2006. Online. Disponível em: http;//www.foodsciencecentral.com/library.html\#ifis/3800.

STAMMEN, K. et al. Modified atmosphere packaging of seafood. Critical Reviews in Food Science and Nutrition, v.29, n.5, p.301-331, 1990.

STANSBY, M. E., GRIFFITHS, F. P. Carbon dioxide in handling fresh fish - haddock. Industrial and Engineering Chemistryn, v. 27, p. 1452-1458, 1935.

VALLEY, G. The effect of carbon dioxide on bacteria. Quarterly Review of Biologyn, v.3, p. 209-224, 1928.

WOLFE, S. K. Use of $\mathrm{CO}$ and $\mathrm{CO}_{2}$ enriched atmospheres for meats, fish, and produce. Food Technology, v. 4, p. 55-58, 1980. 